\title{
Interdisciplinary Systems-Based Intervention to Improve IV Hydration during Parenteral Administration of Acyclovir
}

\author{
Lisa Dubrofsky, Ryan S Kerzner, Chloë Delaunay, Camille Kolenda, Jocelyne Pepin, \\ and Blair C Schwartz
}

\begin{abstract}
Background: Intravenous (IV) hydration is considered a protective factor in reducing the incidence of acyclovir-induced nephrotoxicity. A systemsbased review of cases of acyclovir-associated acute kidney injury can be used to examine institution-, care provider-, and task-related factors involved in administering the drug and can serve as a basis for developing a quality improvement intervention to achieve safer administration of acyclovir.
\end{abstract}

Objectives: To explore the effectiveness of the study institution's interdisciplinary quality improvement intervention in increasing the dilution of acyclovir before IV administration.

Methods: After conducting a systems-based review for intervention development, a retrospective analysis was undertaken to compare IV administration of acyclovir in the 6-month periods before and after implementation of the intervention. The study population was a sequential sample of all patients over 18 years of age who were seen in the emergency department or admitted to a ward and who received at least one IV dose of acyclovir at the study institution. The primary outcome was the volume in which each acyclovir dose was delivered. The secondary outcomes were the hourly rate of fluid administration, the frequency of an increase in hourly hydration rate, and the incidence of acute kidney injury.

Results: Eighty-four patients ( 44 in the pre-intervention period and 40 in the post-intervention period) received IV acyclovir and had evaluable data for the primary outcome. The median volume in which the acyclovir dose was administered was significantly higher in the post-intervention group $(250 \mathrm{~mL}$ versus $100 \mathrm{~mL}, p<0.001)$.

Conclusions: In this study, an easily implemented intervention significantly increased the volume of IV fluid administered to patients receiving acyclovir. Adequately powered prospective studies are suggested to investigate the effectiveness of this intervention on the clinically relevant incidence of acyclovir-induced nephrotoxicity.

Keywords: acyclovir, patient safety, acute kidney insufficiency, medication errors

\section{RÉSUMÉ}

Contexte : L’hydratation par voie intraveineuse est considérée comme un facteur de protection aidant à réduire l'incidence des cas de néphrotoxicité associés à l'acyclovir. Une analyse de systèmes des cas d'insuffisance rénale aiguë associés à l'acyclovir peut servir à examiner les facteurs liés aux établissements, aux fournisseurs de soins et aux tâches qui touchent l'administration du médicament et à générer ainsi une mesure visant l'amélioration de la qualité qui rendra l'administration d'acyclovir plus sûre.

Objectif : Étudier l'efficacité de la mesure interdisciplinaire visant l'amélioration de la qualité qui a été mise en œuvre dans l'établissement de l'étude et qui encourageait à diluer davantage l'acyclovir avant son administration par voie intraveineuse.

Méthodes : Après avoir procédé à une analyse de systèmes pour générer une mesure d'intervention, une analyse rétrospective a été réalisée afin de comparer l'administration d'acyclovir par voie intraveineuse au cours des six mois précédant et suivant la mise en œuvre de la mesure. La population de l'étude était composée d'un échantillon progressif de tous les patients de plus de 18 ans ayant séjourné aux urgences ou dans un service intra-hospitalier et ayant reçu au moins une dose d'acyclovir par voie intraveineuse dans l'établissement concerné. Le principal paramètre d'évaluation était le volume de liquide contenant chaque dose d'acyclovir administrée. Les paramètres d'évaluation secondaires comprenaient : le débit horaire de liquide administré, la fréquence d'ajustement à la hausse du débit liquidien horaire et la fréquence des cas d'insuffisance rénale aiguë.

Résultats : Quatre-vingt-quatre patients (44 dans la période précédant l'application de la mesure et 40 dans la période la suivant) ont reçu de l'acyclovir par voie intraveineuse et présentaient des données évaluables pour le paramètre principal. Le volume médian avec lequel chaque dose d'acyclovir était administrée était significativement supérieur dans le groupe suivant l'application de la mesure $(250 \mathrm{~mL}$ contre $100 \mathrm{~mL}, p<0,001)$.

Conclusions : Cette étude montre qu'une mesure facile à mettre en place augmentait de façon significative le volume de liquides intraveineux administré aux patients recevant de l'acyclovir. L'on suggère de réaliser des études prospectives d'une puissance suffisante pour évaluer l'efficacité de cette mesure en ce qui a trait à la fréquence cliniquement significative des cas de néphrotoxicité associés à l'acyclovir.

Mots clés : acyclovir, sécurité des patients, insuffisance rénale aiguë, erreurs de médicament 


\section{INTRODUCTION}

A cyclovir is an acyclic guanosine derivative with an important therapeutic role in the management of potentially lifethreatening viral infections. IV acyclovir is the primary treatment for herpes simplex encephalitis and is also indicated for severe herpes simplex and varicella zoster virus infections in immunocompromised hosts. ${ }^{1,2}$ However, nephrotoxicity is a serious adverse event that has been well described with IV administration of acyclovir. ${ }^{3}$

The kidneys are the primary means of eliminating acyclovir, accounting for $77 \%$ of total drug clearance, through both glomerular filtration and secretion. ${ }^{4}$ The drug is poorly soluble in urine and can induce renal toxicity through intratubular crystallization, resulting in obstructive nephropathy. Clinically, the acute kidney injury seen with acyclovir is characterized by a decline in renal function within 24 to $48 \mathrm{~h}$ after drug initiation. Although acute kidney injury is typically asymptomatic, the acute kidney injury associated with acyclovir can be associated in rare cases with flank or abdominal pain. ${ }^{5}$

Acyclovir-associated acute kidney injury has been reported in up to $10 \%$ of patients receiving the drug by the IV route. ${ }^{6}$ Proposed strategies to prevent such injury include hydration before and during therapy, appropriate adjustment for the patient's renal function, and avoidance of bolus administration of the drug. ${ }^{5}$ The benefits of hydration and the optimal target population for preventing acyclovir-associated nephrotoxicity have not been evaluated in randomized studies, but data from animal studies and case reports suggest an important role for hydration in maintaining urinary flow during acyclovir administration. $^{7}$ In addition to these data and biologic plausibility, hydration is easy to achieve and unlikely to be associated with significant adverse events.

In response to several cases of acyclovir-associated nephrotoxicity reported at the study institution, the hospital's interdisciplinary medication incident review committee, consisting of physicians, registered nurses, and clinical pharmacists, developed a systemsbased initiative to improve the safety of IV administration of acyclovir. In quality improvement work, systems-based analysis represents the dominant means of analyzing and ultimately responding to adverse events. In a systems-based approach, the various stages of the clinical process are analyzed according to specific categories (including institution-, provider-, and taskrelated factors), to identify areas for prospective interventions. ${ }^{8}$ Rather than focusing on errors at the individual level (e.g., "physician did not prescribe IV fluids"), this type of analysis evaluates the many interdependent factors at the systems levels (e.g., existence or absence of a protocol for prescribing the medication). ${ }^{9}$ This particular analysis followed the approach of Vincent and others, ${ }^{8}$ reviewing each incident with attention to various contributing factors, including institution-, knowledge-, and task-based spheres, to determine the lacunae that allowed the initial error to lead to patient harm.
After initial development and implementation of a quality improvement intervention, it is common to first ensure that the proposed changes or structure can be put into clinical practice, by evaluating a so-called process measure, before studying the effect of the intervention on the clinical outcome of interest. This article describes the process of developing and implementing a systems-based interdisciplinary intervention to improve patient hydration during IV administration of acyclovir. A retrospective before-and-after study was used to evaluate the hypothesis that the quality improvement intervention would lead to an increase in the amount of dilution of acyclovir for IV administration, a process measure. ${ }^{10}$

\section{METHODS}

\section{Intervention}

Several incidents of acyclovir-associated acute kidney injury were reported to the medication incident review committee of the study institution, a university-affiliated, 637-bed acute care teaching hospital. These cases were characterized by increases in serum creatinine, oliguric renal failure, and the need for acute renal replacement therapy. The committee took a systems-based approach to reviewing all of the reported incidents, taking into account the institution-, provider-, and task-related factors contributing to this adverse patient outcome. ${ }^{11}$

The following systems factors were identified in this review: lack of a protocol for administering acyclovir, lack of familiarity with the drug and lack of easily accessible information regarding the recommended dosage, and the manner of preparing and diluting acyclovir for IV administration at the study institution (the drug was often prepared in a $100-\mathrm{mL}$ bag of diluent, at the discretion of the bedside nurse preparing the medication).

After identifying these systems-based deficiencies, the interdisciplinary team analyzed the system that was in place at the time and crafted an intervention that relied on established effective means for targeting systems deficiencies, specifically forcing functions, software enhancements, and cognitive aids to improve the care process, with a view to preventing future adverse events. ${ }^{8}$ Forcing functions are among the strongest of patient safety interventions, in that they do not depend on provider input; rather, they ensure that the task cannot be completed in any other manner. ${ }^{8}$ One famous example of a forcing function was the change in vehicle design to require the driver to have a foot on the brake before shifting into reverse, a change implemented after systems-based reviews of numerous collisions. ${ }^{12}$

Several infrastructure changes in the drug delivery pathway were implemented to improve the safety of IV administration of acyclovir. As a forcing function, the committee mandated that each dose of acyclovir be administered in $250 \mathrm{~mL}$ of diluent, as opposed to nursing staff deciding on their own dilution volume, typically $100 \mathrm{~mL}$. After discussion among healthcare providers 
at the institution, the target of $250 \mathrm{~mL}$ was chosen as a volume sufficient to potentially aid in preventing nephrotoxicity, while still being safe and acceptable on all hospital units. As a software enhancement and additional forcing function, all drug libraries on the IV pumps (Plum A+ pumps with Hospira MedNet Software, Hospira, Lake Forest, Illinois) were updated to ensure a lower volume limit of $250 \mathrm{~mL}$ per dose of acyclovir and to ensure that the rate of administration was no faster than $125 \mathrm{~mL} / \mathrm{h}$. Although limiting the rate of acyclovir infusion was not directly related to the primary outcome, it was thought to be an important aspect of the safe administration of acyclovir and was therefore included in the intervention. The printed nursing medication administration record was updated to serve as a cognitive aid, so that the entry for IV acyclovir contained the following message: "the patient requires ++ IV HYDRATION to prevent kidney injury". In the emergency department, a pop-up reminder was implemented on the dispensing cabinet screen, informing personnel of the need to ensure proper hydration while administering IV acyclovir. To address a lack of familiarity among prescribers as to appropriate medication dosing and the need for optimal hydration, an educational cognitive aid relating to acyclovir use was created and disseminated by e-mail to the hospital's physicians, nurses, and pharmacists; it was also placed in medication binders on each unit and was posted on a shared hard drive available at all networked computers (see Appendix 1, available at www.cjhponline.ca/index.php/cjhp/issue/view/113/showToc). The intervention was rolled out institution-wide on December 1, 2013.

\section{Participants}

A retrospective sequential sample was assembled of all patients over 18 years of age who were seen in the emergency department or admitted to the hospital and who received at least one IV dose of acyclovir at the study hospital during the study periods, as defined below. Eligible patients were identified through the hospital's electronic pharmacy database (GESPHARx8, CGSI@SOLUTIONS-TI Inc, Québec, Quebec), by identifying prescriptions for IV acyclovir within the defined study periods and associating them with unique patient medical record numbers. Patients who received their first dose between May 31 and November 30, 2013, were included in the pre-intervention group, and those receiving their first dose between January 1 and June 30, 2014, were included in the post-intervention group. Patients treated in the month of December 2013, immediately after implementation, were not included in the study.

\section{Outcomes}

The primary outcome was the volume $(\mathrm{mL})$ in which each acyclovir dose was delivered. This process measure was chosen to determine the effectiveness of the quality improvement intervention in actually reaching the patient.

The secondary outcomes were the prescribed rate of infusion $(\mathrm{mL} / \mathrm{h})$, the frequency of an increase in the prescribed infusion rate at the time of acyclovir prescription, and the incidence of acute kidney injury (defined by author consensus, after reviewing the various definitions in case reports of acyclovir-associated nephrotoxicity, as an increase in serum creatinine of at least $30 \%$, based on a comparison of the peak value during acyclovir administration or within 48 hours after discontinuation and the peak value within 48 hours before initiation of administration). The incidence of a doubling of serum creatinine, consistent with "injury" on the RIFLE (Risk, Injury, Failure, Loss of kidney function, and End-stage kidney disease) scale ${ }^{13}$ or stage 2 on the Acute Kidney Injury Network scale ${ }^{14}$ for classification of acute kidney injury, is reported as a post hoc secondary outcome. In cases of administration of acyclovir in the emergency department, the first laboratory value before drug administration was used as the baseline. Patients for whom pre- and post-administration creatinine values were not available were excluded from analysis of creatinine-related outcomes.

This study was approved by the Research Ethics Committee of the Sir Mortimer B Davis Jewish General Hospital.

\section{Statistical Analysis}

Statistical analysis was performed with Stata 12 software (StataCorp, College Station, Texas) with a prespecified 2-tailed significance level of $p<0.05$. All outcome measures and analytic techniques were determined before initiation of data collection and analysis, unless otherwise specified. Continuous data were analyzed by the Shapiro-Wilk test, which showed a non-normal distribution; these data are therefore reported as medians and interquartile ranges. The Wilcoxon rank-sum test was used for the analysis of statistical differences between medians. Categorical data were analyzed with the Pearson $\chi^{2}$ test.

\section{RESULTS}

\section{Participants}

Eight-eight unique prescriptions for IV acyclovir were identified over the study periods. Three patients were excluded as they did not receive the prescribed medication, and one patient was excluded because therapy was initiated at another institution, which left 84 patients eligible for analysis of the primary outcome, 44 in the pre-intervention group and 40 in the postintervention group. Of these, 5 patients had missing data for hydration status, and 8 patients did not have the necessary laboratory data to evaluate drug-induced acute kidney injury, which left 79 and 76 patients, respectively, for analysis of the secondary outcomes. 
This single copy is for your personal, non-commercial use only.

For permission to reprint multiple copies or to order presentation-ready copies for distribution, contact CJHP at cjhpedit@cshp.ca

Table 1. Demographic and Clinical Characteristics of Study Participants

\begin{tabular}{|c|c|c|c|}
\hline \multirow[b]{2}{*}{ Characteristic } & \multicolumn{2}{|c|}{ Timing; No. (\%) of Patients* } & \multirow[b]{2}{*}{$p$ Value } \\
\hline & $\begin{array}{l}\text { Before Intervention } \\
(n=44)\end{array}$ & $\begin{array}{l}\text { After Intervention } \\
\quad(n=40)\end{array}$ & \\
\hline Age (years), median (IQR) & $66.5(38.0-76.5)$ & $57.0(36.5-71.5)$ & 0.16 \\
\hline Sex, male & $20(45)$ & $19(48)$ & 0.85 \\
\hline Hospital unit & & & NA \\
\hline Emergency department & $11(25)$ & $5(12)$ & \\
\hline Medical ward & $28(64)$ & $27(68)$ & \\
\hline Surgical ward & 1 (2) & $5(12)$ & \\
\hline $\begin{array}{l}\text { Other (cardiology, intensive care, } \\
\text { maternity, psychiatry) }\end{array}$ & $4 \quad(9)$ & $3 \quad(8)$ & \\
\hline Baseline creatinine $(\mu \mathrm{mol} / \mathrm{L})$, median $(\mathrm{IQR}) \dagger$ & $84(61-137)$ & $77.5(54-93)$ & 0.21 \\
\hline $\mathrm{eGFR}\left(\mathrm{mL} \mathrm{min}^{-1} 1.73 \mathrm{~m}^{-2}\right)$, mean \pm SD $†$ & $78 \pm 41$ & $93 \pm 41$ & 0.12 \\
\hline $\mathrm{eGFR}<30 \mathrm{~mL} \mathrm{~min}-11.73 \mathrm{~m}^{-2} \dagger$ & $5 / 41(12)$ & $1 / 39 \quad(3)$ & 0.10 \\
\hline Indication for acyclovir & & & NA \\
\hline Herpes meningoencephalitis & $32(73)$ & $24(60)$ & \\
\hline Stomatitis & $3(7)$ & $10(25)$ & \\
\hline Herpes zoster & $3(7)$ & 2 (5) & \\
\hline Esophagitis & $1 \quad(2)$ & $2 \quad(5)$ & \\
\hline Disseminated herpes virus infection & $2 \quad(5)$ & 0 & \\
\hline Immunocompromised host & $1 \quad(2)$ & $1 \quad(2)$ & \\
\hline Genital infection & 2 (5) & $1 \quad(2)$ & \\
\hline Duration of acyclovir therapy (h), median (IQR) & $46.5(12-100.5)$ & $58.75(31.5-97)$ & 0.41 \\
\hline
\end{tabular}

Table 2. Hydration-Related and Acute Kidney Injury Outcomes

\begin{tabular}{|c|c|c|c|}
\hline \multirow[b]{2}{*}{ Outcome } & \multicolumn{2}{|c|}{ Timing; No. (\%) of Patients* } & \multirow[b]{2}{*}{$p$ Value } \\
\hline & $\begin{array}{l}\text { Before Intervention } \\
\quad(n=44)\end{array}$ & $\begin{array}{l}\text { After Intervention } \\
\quad(n=40)\end{array}$ & \\
\hline Dilution volume per dose of acyclovir (mL), median & 100 & 250 & $<0.001$ \\
\hline Rate of IV hydration (mL/h), median (IQR) & $\begin{array}{c}100(80-150) \\
(n=40)\end{array}$ & $\begin{array}{c}100(100-150) \\
(n=39)\end{array}$ & 0.19 \\
\hline Rate of IV hydration increased at acyclovir initiation & $\begin{array}{l}15(41) \\
(n=37)\end{array}$ & $\begin{array}{l}22(56) \\
(n=39)\end{array}$ & 0.17 \\
\hline Drug-induced AKI (30\% increase in SCr) & $\begin{array}{c}7(18) \\
(n=38)\end{array}$ & $\begin{array}{c}8(21) \\
(n=38)\end{array}$ & 0.77 \\
\hline Doubling of $\mathrm{SCr}$ & $\begin{array}{c}5(13) \\
(n=38)\end{array}$ & $\begin{array}{c}0(0) \\
(n=38)\end{array}$ & 0.021 \\
\hline
\end{tabular}

$\mathrm{AKI}=$ acute kidney injury, IQR = interquartile range, $\mathrm{SCr}=$ serum creatinine.

*Except where indicated otherwise.

Clinical and demographic characteristics were similar between the pre- and post-intervention groups, with most patients receiving IV acyclovir for treatment of suspected herpes meningoencephalitis (Table 1).

\section{Outcomes}

The primary outcome, the volume in which each acyclovir dose was administered, was significantly higher in the postintervention group (median $250 \mathrm{~mL}$ versus $100 \mathrm{~mL}, p<0.001$ ).

The median rate of administration of IV fluid was similar between the 2 groups ( $100 \mathrm{~mL} / \mathrm{h}$ for both groups, $p=0.19$ ) (Table 2). After the intervention, the rate of infusion of IV fluid was more frequently increased at the time of acyclovir initiation, but the difference was not statistically significant (56\% versus $41 \%$ of patients, $p=0.17$ ) (Table 2).

Seven patients in the pre-intervention group and 8 patients in the post-intervention group met the prespecified criteria for acute kidney injury, specifically a $30 \%$ increase in serum creatinine ( $18 \%$ versus $21 \%, p=0.77$ ). Details regarding baseline and peak creatinine values for these 15 patients are provided in Table 3 . Five patients in the pre-intervention group and none in the post-intervention group experienced the post hoc outcome of a doubling in serum creatinine ( $13 \%$ versus $0 \%, p=0.021$ ).

\section{DISCUSSION}

To the authors' knowledge, this is the first study describing the development, implementation, and effectiveness of a quality 
This single copy is for your personal, non-commercial use only.

For permission to reprint multiple copies or to order presentation-ready copies for distribution, contact CJHP at cjhpedit@cshp.ca

Table 3. Laboratory Data for Patients with Acute Kidney Injury

\begin{tabular}{lrc} 
& \multicolumn{2}{c}{ Serum Creatinine $(\boldsymbol{\mu m o l} / \mathbf{L})$} \\
\cline { 2 - 3 } Patient no. & Baseline & Peak \\
\hline Pre-intervention group & 56 & 320 \\
1 & 46 & 63 \\
2 & 55 & 140 \\
3 & 76 & 104 \\
4 & 143 & 286 \\
5 & 166 & 489 \\
6 & 39 & 89 \\
7 & & \\
\hline Post-intervention group & 35 & 47 \\
1 & 44 & 66 \\
2 & 195 & 298 \\
3 & 54 & 105 \\
4 & 116 & 153 \\
5 & 113 & 162 \\
6 & 40 & 53 \\
7 & 125 & 170 \\
8 & &
\end{tabular}

improvement intervention aimed at increasing IV hydration to improve the safety of IV administration of acyclovir. These data show that an intervention derived from a systems analysis and incorporating a forcing function, with cognitive aids and software enhancements, led to a significant increase in the total amount of IV fluid administered, the primary process measure outcome. In addition, although there was no reduction in the prespecified outcome of acute kidney injury, there was a significant reduction in the post hoc outcome of a doubling of serum creatinine. This indicates that the intervention was effectively translated from a policy or structure into a clinical process that reached the patient, one with the potential to prevent clinically relevant adverse events.

Interdisciplinary systems-based analysis has been the cornerstone of some of the most significant work in patient safety. The participation of members from multiple disciplines was integral to the analysis described here, and the multidisciplinary format allowed each member to propose challenges and solutions within their respective domains at all steps in the drug delivery pathway, from prescription to preparation and administration of the drug. Pharmacists were able to comment on an acceptable concentration for dilution, nurses could rely on their experience to suggest intervention elements that would reach the bedside, and physicians could comment on the safety and appropriateness of increased hydration for all patients. Additionally, when crafting an intervention like this, the involvement of all disciplines fosters buy-in for the proposed changes and helps in identifying barriers to implementation in each domain. The necessity of such interdisciplinary composition is further highlighted by its mandatory nature within the CUSP method (Comprehensive Unit-based Safety Program), one of the most widely applied and highly respected means for improving unit-based safety culture. ${ }^{15}$
In their landmark publication on the reduction of central line-associated bloodstream infections, Pronovost and others ${ }^{16}$ similarly started with an analysis of systems-based factors that prevented compliance with the best evidence-based practice for line insertion. Although they were ultimately able to demonstrate a significant reduction in the clinically important outcome of central line-associated bloodstream infection rate, ${ }^{16}$ early work by this group involved auditing baseline and post-intervention compliance with the infection prevention measures proposed in their intervention, a process measure similar to the primary outcome in the current study. Pronovost and others ${ }^{16}$ applied their quality intervention in a geographically isolated unit, such as the intensive care unit, but the intervention described here had to be adopted throughout all hospital departments by various personnel. For this reason, inclusion of a forcing function was of utmost importance in ensuring practice change in a variety of clinical settings.

In a prospective study targeting the reduction of urinary catheter use and related urinary tract infections, Schwartz and others ${ }^{17}$ provided a brief monthly in-person educational intervention to physicians and nurses, highlighting the findings of their systems-based review of the problem. Through this intervention, which had a different format but similar aim to the cognitive aid-based educational materials used in the current study, they achieved a 50\% reduction in catheter utilization rates, demonstrating the success of a proactive educational intervention in improving a process measure. Their work was also limited to a single clinical unit, which permitted tailoring of the intervention to unit needs, in contrast to the hospital-wide intervention in the current study, which required more broad-based acceptance and, as such, a forcing function.

Utilization of a process measure, as opposed to a more clinically relevant outcome measure, has been described for other patient safety initiatives. Interventions to target enhanced compliance with venous thromboembolism (VTE) prophylaxis among medical inpatients, for whom reduction in VTE is less clear than in the post-orthopedic surgery population, is a well-known example. ${ }^{18}$ The clinical and biologic plausibility of the intervention, as well as the low risk of harm in providing VTE prophylaxis, is similar to that seen with the administration of IV fluids to prevent acyclovir-associated nephrotoxicity. The structure, process, and outcome hierarchy of metrics for evaluating the effectiveness of quality improvement interventions is well established. ${ }^{19}$

This study was successful in improving the process measure of IV fluid hydration, but there was no reduction in the prespecified secondary outcome of acyclovir-associated nephrotoxicity. However, a significant absolute reduction was observed in the incidence of the post hoc outcome of serum creatinine doubling. It remains unknown whether this reflects a spurious finding or provides support that the intervention is more effective 
in preventing severe, rather than mild, acute kidney injury. We therefore suggest that future workers in this field adopt doubling of serum creatinine as a primary clinical outcome measure. Apart from an increase in the required sample size, there are additional complications to using drug-induced kidney injury as a clinical outcome measure, particularly for retrospective studies. The multifactorial nature of acute kidney injury in hospital inpatients, the presence of other confounding medications or etiologies, and the limitations of using serum creatinine as a marker of clinically significant acute kidney injury are challenges to studying this clinically relevant outcome. ${ }^{20}$

The limitations of this study included its single-centre nature and the potential for misclassification of outcome measures. Although this was a single-centre study, the large size of the institution, the supra-regional catchment area, and the inclusion of all hospital wards increased the external validity of the work. Furthermore, the observed incidence of acyclovirinduced nephrotoxicity was consistent with what has been reported in other studies, which suggests a patient and practice profile similar to that of other centres. ${ }^{3}$ As with any retrospective study, there was a risk of misclassification bias for the outcome measures. Although the data collectors were not blinded to participants' group assignments, the component data of all outcome measures were purely numeric and were objectively defined, which was thought to minimize potential bias in this regard. As well, because of limitations in patient numbers available before the intervention, it was not possible to conduct power calculations and adjust sample size accordingly.

This work, though preliminary in nature, does have potential implications for practice. First, it shows that an interdisciplinary systems-based analysis is an effective means of crafting safety interventions that can effect change at the patient level. As such, we strongly suggest adoption of this modality by institutions when they are reviewing medication-related adverse events. Second, although benefits were seen only in a process outcome and the post hoc renal failure outcome, increased hydration may have intrinsic face value, given its biologic plausibility and favourable safety profile. As such, institutions may consider implementation of this intervention to increase hydration in cases of acyclovir administration, even in the absence of a conclusively demonstrated benefit in terms of the incidence of acute kidney injury.

\section{CONCLUSION}

In this study, use of an easily applied intervention increased the amount of IV fluid administered to patients who were receiving acyclovir, a potentially nephrotoxic medication. Current recommendations highlight the importance of hydration during acyclovir administration, and this study lays the groundwork for future performance of an adequately powered, prospective, controlled study to determine whether this intervention to increase hydration reduces the clinically relevant incidence of acyclovir-induced acute kidney injury, as defined by a doubling in serum creatinine, in the hospital setting.

\section{References}

1. Whitley RJ, Gnann JW Jr. Acyclovir: a decade later. N Engl J Med. 1992; 327(11):782-9.

2. Levitz RE. Herpes simplex encephalitis: a review. Heart Lung. 1998; 27(3):209-12.

3. Perazella MA. Drug-induced renal failure: update on new medications and unique mechanisms of nephrotoxicity. Am J Med Sci. 2003;325(6):349-62.

4. Laskin OL, Longstreth JA, Saral R, de Miranda P, Keeney R, Lietman PS. Pharmacokinetics and tolerance of acyclovir, a new anti-herpesvirus agent, in humans. Antimicrob Agents Chemother. 1982;21(3):393-8.

5. Perazella MA. Crystal-induced acute renal failure. Am J Med. 1999; 106(4):459-65.

6. Acyclovir (systemic). In: Lexicomp online [database on Internet]. Hudson (OH): Wolters Kluwer; [cited 2015 Apr 28]. Available from: http://online. lexi.com/lco/action/doc/retrieve/docid/dental_f/2074419\#. Subscription required to access content.

7. Sawyer MH, Webb DE, Balow JE, Straus SE. Acyclovir-induced renal failure. Clinical course and histology. Am J Med. 1988;84(6):1067-71.

8. Vincent C, Taylor-Adams S, Stanhope N. Framework for analysing risk and safety in clinical medicine. BMJ. 1998;316(7138):1154-7.

9. Gosbee J, Anderson T. Human factors engineering design demonstrations can enlighten your RCA team. Qual Saf Health Care. 2003;12(2):119-21.

10. Mainz J. Defining and classifying clinical indicators for quality improvement. Int J Qual Health Care. 2003;15(6):523-30.

11. Vincent C. Understanding and responding to adverse events. $N$ Engl J Med. 2003;348(11):1051-6.

12. Norman DA. The design of everyday things. New York (NY): Doubleday/ Currency; 1988.

13. Bellomo R, Ronco C, Kellum JA, Mehta RL, Palevsky P; Acute Dialysis Quality Initiative workgroup. Acute renal failure - definition, outcome measures, animal models, fluid therapy and information technology needs: the Second International Consensus Conference of the Acute Dialysis Quality Initiative (ADQI) Group. Crit Care. 2004;8(4):R204-12.

14. Mehta RL, Kellum JA, Shah SV, Molitoris BA, Ronco C, Warnock DG, et al.; Acute Kidney Injury Network. Acute Kidney Injury Network: report of an initiative to improve outcomes in acute kidney injury. Crit Care. 2007;11(2):R31.

15. Pronovost PJ, King J, Holzmueller CG, Sawyer M, Bivens S, Michael M, et al. A web-based tool for the Comprehensive Unit-based Safety Program (CUSP). Jt Comm J Qual Patient Saf. 2006;32(3):119-29.

16. Pronovost P, Needham D, Berenholtz S, Sinopoli D, Chu H, Cosgrove S, et al. An intervention to decrease catheter-related bloodstream infections in the ICU. N Engl J Med. 2006;355(26):2725-32.

17. Schwartz BC, Frenette C, Lee TC, Green L, Jayaraman D. Novel lowresource intervention reduces urinary catheter use and associated urinary tract infections: role of outcome measure bias? Am J Infect Control. 2015; 43(4):348-53.

18. Kakkar AK, Cimminiello C, Goldhaber SZ, Parakh R, Wang C, Bergmann JF; LIFENOX Investigators. Low-molecular-weight heparin and mortality in acutely ill medical patients. N Engl J Med. 2011;365(26):2463-72.

19. Berenholtz SM, Pustavoitau A, Schwartz SJ, Pronovost PJ. How safe is my intensive care unit? Methods for monitoring and measurement. Curr Opin Crit Care. 2007;13(6):703-8.

20. Parikh CR, Devarajan P. New biomarkers of acute kidney injury. Crit Care Med. 2008;36(4 Suppl):S159-65.

Lisa Dubrofsky, MDCM, is an Internal Medicine Resident with the Department of Medicine, McGill University, Montréal, Quebec. 
Ryan S Kerzner, BPharm, MSc, is an Antimicrobial Stewardship Pharmacist with the Department of Pharmacy, Sir Mortimer B Davis Jewish General Hospital, Montréal, Quebec.

Chloë Delaunay is a pharmacy student with the Faculté des sciences pharmaceutiques et biologiques, Université de Nantes, Nantes, France. At the time of the study, she was on an elective rotation with the Department of Pharmacy, Sir Mortimer B Davis Jewish General Hospital, Montréal, Quebec.

Camille Kolenda is a pharmacy student at Université Claude Bernard Lyon 1, Lyon, France. At the time of the study, she was on an elective rotation with the Department of Pharmacy, Sir Mortimer B Davis Jewish General Hospital, Montréal, Quebec.

Jocelyne Pepin, MSc, is Assistant Director of the Department of Pharmacy, Sir Mortimer B Davis Jewish General Hospital, Montréal, Quebec.
Blair C Schwartz, MDCM, MHS, FRCPC, is an Attending Physician, Division of Internal Medicine and Department of Adult Critical Care, Sir Mortimer B Davis Jewish General Hospital, and an Assistant Professor, Department of Medicine, McGill University, Montréal, Quebec

Competing interests: None declared.

\section{Address correspondence to:}

Dr Blair Schwartz

Division of Internal Medicine

Sir Mortimer B Davis Jewish General Hospital

3755, chemin de la Côte-Sainte-Catherine

Montréal QC H3T 1E2

e-mail: blaircarl.schwartz@mcgill.ca

Funding: None received.

\section{Compounding: Guidelines for Pharmacies 2014}

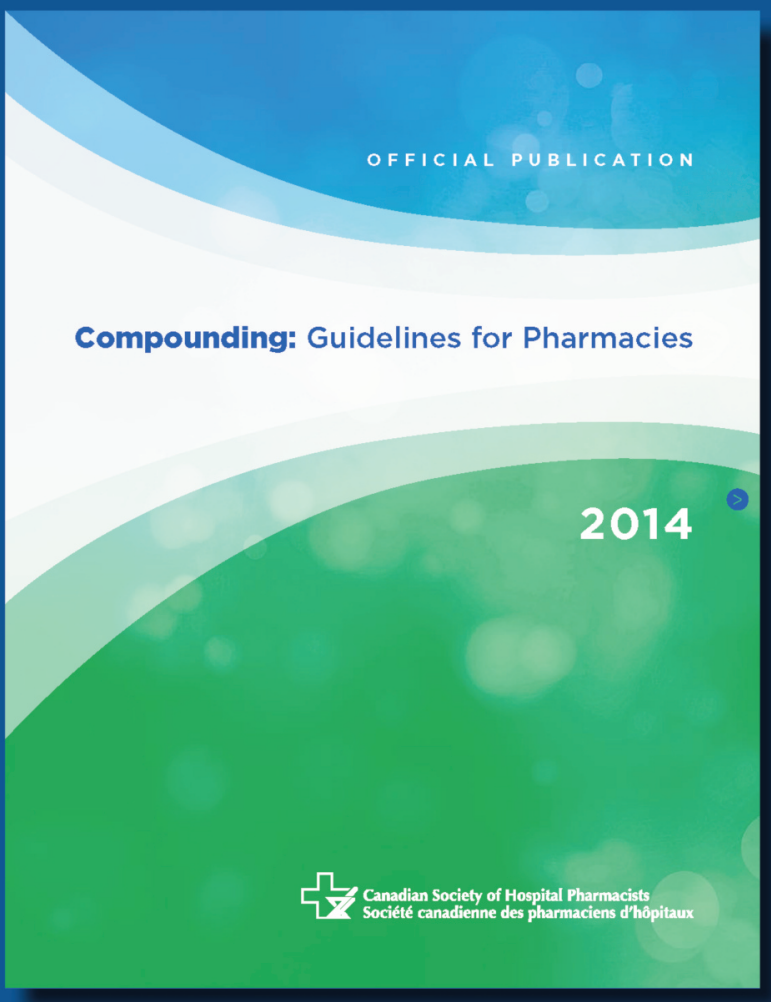

The Canadian Society of Hospital Pharmacists' comprehensive set of guidelines covers the compounding in pharmacies whenever compounded preparations are intended for human use, regardless of the route of administration or whether the preparation is related to research purposes. These guidelines also apply to the preparation of radiopharmaceuticals and other hazardous pharmaceuticals.

Find our order form here: http://www. cshp.ca/dms/dmsView/I CSHP-Publications-form-Jan2015.pdf

Contact the CSHP Publications Administrator for more information:

E: aiannaccio@cshp.ca

P: 6 | 3-736-9733 x:228 